\title{
Arte afrobrasileira: contornos dinâmicos de um conceito
}

\author{
Afro-Brazilian Art: contours of a dynamic concept
}

por Nelma Cristina Silva Barbosa de Mattos

\section{RESUMO}

Partindo de uma revisão de literatura, o artigo apresenta as principais tendências para a abordagem do conceito de arte afrobrasileira, bem como alguns dos seus autores mais destacados. Ressalta importantes teóricos que se tornaram referência para estudos da temática. Descreve o panorama da construção do conceito, que surge devido sua relação com os estudos sobre os negros no âmbito da Medicina. A visão contemporânea do tema se abre a uma certa diversidade de interpretações possíveis. Ao pontuar aspectos históricos do surgimento desses estudos, analisa sua relação com a história da arte e com a questão da identidade nacional, bem como confirma a importância da sistematização de informações e conhecimento sobre a contribuição negra na arte do Brasil.

Palavras-Chave: Arte Afrobrasileira, Conceito, Intelectuais, Identidade Nacional.

\section{ABSTRACT}

Based on a literature review, the paper presents the main trends in discussing the concept of Afro-Brazilian art, as well as some of its most prominent artists. It highlights important theorists that have become reference for these studies while also providing an overview of the concept's construction, which arises due to its relation with medical studies about blacks. However, the contemporary view of the subject opens up to a certain range of possible interpretations. Upon pointing to the historical emergence of these studies, this study in particular analyzes their relationship with art history and the question of Brazilian national identity, and confirms the importance of the systematization of information and knowledge about the contributions of blacks to art in Brazil.

Keywords: Afro-Brazilian Art, Concept, Intellectuals, National Identity. 


\section{Introdução}

A produção artística negro-brasileira encontrou momentos diferenciados até se consolidar como um importante campo de estudos da arte nacional. Isto se deu justamente porque a discussão em torno de uma arte de expressão negra tem fronteiras muito fluídas com o debate sobre as questões identitárias do Brasil. 0 tema configurou-se como um espaço de disputas de muitas ideias, tensões e conflitos, reflexos da complexidade e das transformações que o tema da identidade brasileira assumiu, particularmente após a Abolição da Escravatura, em 1888. Portanto, o vínculo etnicorracial que acompanha essa arte não nos permite uma visão apenas formalística, mas sobretudo, nos obriga a contextualizar a situação da população de origem africana no país, estabelecendo assim, conexões entre as subjetividades forjadas nas relações raciais brasileiras.

Desse modo, em um estudo sobre a arte afrobrasileira é necessário se considerar o papel da arte na definição da auto-imagem de um povo, e a força que esta tem para representar ideias. É nesse cenário que o conceito de Arte Afrobrasileira aparece, demonstrando a diversidade que sempre acompanhou os estudos sobre a participação dos negros e mestiços na cultura do Brasil. Embora sintetize uma dinâmica intensa de ideias e de tendências, usaremos no presente artigo, o termo arte afrobrasileira de acordo com a indicação da pesquisadora Marta Salum (2000, p.113), que define a arte afrobrasileira como "qualquer manifestação plástica e visual que retome, de um lado, a estética e a religiosidade africanas tradicionais e, de outro, os cenários socioculturais do negro no Brasil". Como afirmamos anteriormente, a produção artística dos negros no Brasil abrange hoje um relevante capítulo na Arte Brasileira, assim como na história de sua população. Além disso, cabe-nos buscar compreender as implicações do meio acadêmico nesse processo, revisitando e problematizando algumas estratégias implementadas para a explicação das manifestações culturais e artísticas dos negros. Nosso trabalho visa refletir brevemente sobre o panorama da construção da noção de arte afrobrasileira, trazendo a contribuição de alguns intelectuais para a sustentação das principais abordagens conceituais da presença negra nas artes plásticas do Brasil.

\section{Um Trajeto Sinuoso}

0 final do século XIX e as primeiras décadas do século seguinte constituíram um momento de importantes e definitivos estudos sobre a contribuição negra na sociedade brasileira. Porém, a maioria desses estudos focava os aspectos da religiosidade e da escravidão. Nesse período, muitas práticas culturais das populações descendentes de africanos eram perseguidas e combatidas, a exemplo da capoeira e do candomblé, tratados como questão de polícia.

As religiões afrobrasileiras eram vítimas constantes de diligências policiais que não só encarceravam seus fiéis, como também apreendiam provas materiais da "cena do crime", ou seja, confiscavam toda a imaginária sacra e demais materiais utilizados nos 


\section{Arte afrobrasileira: contornos dinâmicos de um conceito}

cultos como vestimentas, alimentos, entre outros. 0 espaço da religião permitiu que muitos aspectos da vida social africana fossem reativados e recriados, incluindo a criação artística, a qual seguia outros cânones e referências estéticas diferentes da arte europeia. 0 resultado das apreensões dos objetos dos cultos das religiões afrobrasileiras constituíram acervos de museus da polícia, pois estes passaram a ter posse de exemplares significativos de reelaborações do arcabouço artístico negro após a sua captura.

Os estudos realizados sobre esses acervos foram fundamentais para um entendimento inicial sobre arte afrobrasileira, tais como as análise desses objetos, realizadas por Nina Rodrigues, Arthur Ramos e Clarival do Prado Valladares. Mas, para Munanga (2000), olhares sobre o tema afrobrasileiro nos trabalhos artísticos serão estimulados a partir da realização dos dois Congressos Afrobrasileiros (o primeiro em Recife, 1934, e depois em Salvador,1937); soma-se aí também as missões folclóricas organizadas nas regiões Norte e Nordeste por Mário de Andrade, entre 1937-38.

Nos anos 1930 e 1940, alguns negros começaram a ser inseridos como artistas populares ou primitivos, ampliando o locus de criação para além dos espaços religiosos. 0s artistas sairão do anonimato, mas conservarão os vínculos identitários.

Na segunda metade do século XX, a produção dos negros do Brasil passa a integrar o que a história da arte convencionou chamar de Arte Popular e que, em seguida, rebatizou como Arte Primitiva. Essa última nomenclatura se deu por causa da relação da arte africana com o modernismo, que acionou novas possibilidades estéticas a partir de culturas negras. Mas, mesmo considerada inferior, infantil ou primitiva, a arte negra conseguiu engrenar um período de longo retorno financeiro para seus operadores. Além disso, os artistas modernos desejavam a vinculação do nacional com o popular (CONDURU, 2007, 2013a), o que repercutia também nas identidades, em suas referências político-ideológicas e, claro, nos processos criativos.

Outros estudos importantes foram realizados na segunda metade do século, destacando-se os estudos sobre peças dos acervos dos museus das policias de Alagoas, Rio de Janeiro, Bahia, etc., apreendidas ainda em fins do século XIX e início do XX. Clarival do Prado Valladares foi um dos críticos de arte que se empenhou bastante em pesquisas sobre os artistas negros nos anos 1960. No entanto, os estudos nesse campo ressurgiram com intensidade no país a partir do centenário da Abolição da Escravatura, em 1988. (CUNHA et al., 2006; SALUM, 2004).

\section{Entre Artífices, Artesãos e Artistas}

Estabelecer uma data para o surgimento de uma arte afrobrasileira seria algo muito difícil, pois, segundo o antropólogo Kabengele Munanga (2000), esta se desenvolveu na clandestinidade. Para o autor, "a primeira forma de arte plástica afrobrasileira propriamente dita é uma arte ritual, religiosa" (MUNANGA, 2000, p. 104), marcada por seu caráter coletivo, o que impediu a identificação de seus autores. Além disso, o tema não foi ainda explorado suficientemente em pesquisas científicas, o que nos deixa longe de constituir um quadro com maior precisão. 0 curador e artista Emanoel Araújo (1988, 
p.16) queixa-se, entretanto, do desinteresse dos estudiosos da questão negra no Brasil para as artes plásticas:

\begin{abstract}
“E, na verdade, não se pode dizer que a vigorosa contribuição do negro à formação de uma cultura legitimamente brasileira não tenha interessado aos nossos estudiosos. Essas pesquisas, todavia, têm praticamente se limitado à escravidão propriamente dita e à herança negra encontrada no sincretismo religioso, na música, no idioma, na literatura e nos costumes. As artes plásticas sempre foram relegadas a plano secundário, limitando-se praticamente a trabalhos isolados e incompletos. No entanto, não existiria hoje uma arte legitimamente brasileira sem a criativa e poderosa influência do negro"
\end{abstract}

A divulgação e a sistematização de informações sobre a arte dos negros no Brasil só foi possível a partir dos estudos pioneiros do médico Raymundo Nina Rodrigues, em 1904. Mas, para muitos especialistas no assunto (SALUM, 2004; SILVA e CALAÇA, 2006; DIAS, 2009), é possível localizar o protagonismo negro nas manifestações plásticas do país no momento anterior à instalação de um sistema de instrução oficial para os artistas da colônia. Tal sistema tem como emblema a vinda, em 1816, da Missão Artística Francesa (MAF).

A MAF foi um grupo de artistas estrangeiros contratado pelo imperador para a criação da Academia Imperial de Belas Artes, no Rio de Janeiro. 0 modelo a ser seguido era 0 do principal centro de ensino artístico daquela época: o da Académie Royale de Peinture et Sculpture, fundada em Paris no ano de 1648.

Até o momento da chegada desses profissionais europeus, não havia separação entre as categorias de artesão e de artista. Toda a produção artística local tinha como referência a arte europeia, mas era realizada por mestiços, indígenas e africanos. A contribuição do negro na arte dessa época pode ser mais claramente notada através da decoração, da imaginária e da arquitetura religiosa. Segundo Silva e Calaça (2006), o clero determinava as produções artísticas oficiais, que consistiam em imagens sacras, objetos de rituais católicos, mobiliários e altares.

As obras do mineiro Antônio Francisco Lisboa, o Aleijadinho (1730-1814) são exemplos marcantes do período, que ficou conhecido na História da Arte como o barroco brasileiro. Esse estilo comprova que, mesmo seguindo os cânones artísticos da Europa, marcas sensíveis do arcabouço estético dessas populações eram impressas em tudo o que realizavam, conforme relata a pesquisadora Mariza Dias (2009 apud CONDURU e SIQUEIRA, 2009, p.468):

Quando nos referimos à produção artística com influência negra do período colonial e imperial, falamos de obras feitas por negros ou mulatos que trabalham com uma visão europeia. As imagens produzidas no barro e madeira do barroco brasileiro são realizadas a partir de cópias de estampas encomendadas na Europa, contudo se observarmos sua fatura técnica, se analisarmos os atributos dos santos, encontraremos características africanas, como podemos notar nas feições negroides de alguns anjos e madonas do período. 
A Missão Artística Francesa acabou por impor à colônia o olhar europeu na produção artística brasileira, o que interrompeu o desenvolvimento de uma criação com referenciais diversos. A academia na colônia também estabeleceu diferenças para as categorias de artista e de artesão. 0 primeiro, que desfrutava de relativos privilégios naquela sociedade, era proveniente das camadas sociais mais abastadas - e brancas, portanto. Os artesãos constituíam o grupo de trabalhadores que sustentava aquela economia colonial, ainda baseada no trabalho escravo. Entretanto, a academia recebeu e formou artistas negros, mesmo escravizados.

\section{Pensando Racialmente a Arte}

Paralelo ao processo de institucionalização do ensino da arte no Brasil, as religiões de matriz africana começavam a adquirir os formatos que conhecemos hoje. Os terreiros de candomblé se consolidavam como espaços de ressocialização de negras e negros escravizados. Nesses novos territórios era possível a materialização de certos aspectos da vida no continente africano, como por exemplo, a utilização da arte para a comunicação de símbolos e valores coletivos imprescindiveis para aquele grupo. Assim, africanos e seus descendentes davam forma à elementos reminiscentes das culturas materiais da África que se manifestavam e se recriavam no Brasil.

0 antropólogo Arthur Ramos (1988, p.252) afirma que "os negros escondiam suas manifestações de arte no recesso dos candomblés, onde continuaram a esculpir na madeira seus ídolos e emblemas e a fabricar objetos do culto, da mesma forma como faziam na África." Nesse mesmo artigo, o autor ainda apresenta o terreiro de candomblé como espaço de sobrevivência da liberdade da criação, ainda limitada a expressão tridimensional. Aponta que havia um intenso trânsito de informações e de objetos, fazendo com que algumas peças viessem da África e que fossem guardadas em candomblés, principalmente nos baianos. Sobre isso, complementa o crítico de arte Mário Barata:

\footnotetext{
...de toda ou grande parte da América do sul, só o nosso país (Bahia, durante muito tempo, Rio) parecem ter se conservado de maneira evidente, as técnicas e concepções plásticas africanas. Durante esse tempo muitas peças foram trazidas da África ou feitas aqui por africanos até o início do século XX. Uma vez cessado esse contato, formou-se na Bahia um centro de escultura destinado a abastecer os terreiros. Esses escultores eram certamente descendentes de africanos ligados ao culto. (BARATA, 1988, p. 183 apud SILVA, 2012)
}

Para esse influente formador de opiniões do século XX, pintura e desenho não teriam sido áreas de relevante produção e continuidade para os negros. Mário Barata, assim como muitos outros brasileiros no meio da arte, nasceram e viveram envoltos no mito da democracia racial. 0 famoso crítico não problematizava a ausência de negros no sistema da arte, embora seu trabalho facilitasse articulações mercadológicas com obras de artistas negros.

Souza (2009) alerta que em finais do século XIX e início do XX, iniciava-se certa racializa- 
ção da arte brasileira, pois a crítica especializada de arte já apontava a presença negra no meio artístico como algo de relevância e peculiaridades. 0 autor cita os exemplos dos intelectuais Luiz Gonzaga - Duque Estrada e Mário de Andrade que dialogaram sobre uma arte genuinamente brasileira.

Duque Estrada defendia a arte europeia como principal referência para os brasileiros. Entretanto, traduzia em seus escritos a influência que a noção de raça tinha naquele tempo. Ele apontava uma arte futura, fruto da miscigenação, mas trazia à tona os conflitos entre o pessimismo e a euforia com o futuro da nação.

Enquanto isso, Mário de Andrade chamava a atenção para a condição de mulato de Antônio Francisco Lisboa, o Aleijadinho. Esse artista tornou-se o ícone da arte de estilo barroco brasileiro, e seu pertencimento racial, segundo Andrade, teria sido a condição determinante para o tipo de trabalho que o escultor realizara. 0 valor dado à condição mulata do artista contrastava com as ideias do século anterior, que valorizavam a influência europeia da academia. Essa visão positiva da miscigenação seria um eixo importante para o modernismo brasileiro, movimento cultural no qual Mário de Andrade destacou-se como um dos principais integrantes.

\section{A Religião Como Ponto de Partida}

Os estudos sobre a arte afrobrasileira são marcados pelo trabalho precursor de Raymundo Nina Rodrigues. 0 seu artigo "As Belas Artes nos Colonos Pretos do Brasil", publicado na revista Kosmos, em 1904, inaugurou os estudos sobre arte negra, mesmo sendo a única produção do autor sobre este assunto. Ainda que a intenção de Nina fosse mostrar cientificamente a inferioridade dos negros na Bahia, ele conseguiu produzir uma importante obra, tornando-se um dos principais autores do tema.

0 médico denominava arte negra o que chamamos hoje de arte afrobrasileira, mas suas reflexões se davam através do enfoque na arte iorubana e da análise de objetos ritualísticos. Adotando uma "perspectiva evolucionista etnocêntrica em busca da solução desta questão de higiene social" (CUNHA et al., 2006, p.24), Rodrigues foi ousado e original em refletir sobre a "questão negra" naquela época e ainda, em nomear de "arte" toda aquela produção. A até então, a produção material da população negra era vista apenas como documento, como testemunha do atraso e do primitivismo daquele grupo. A temática negra ou africana não era comum entre os estudiosos.

Esse tipo de abordagem centrada na arte iorubana e sacra, foi alterada por Arthur Ramos, em 1956. 0 antropólogo não só analisaria o material deixado por Nina, recolhido nos candomblés baianos, mas ampliaria o acervo estudado com trabalhos de artistas laicos, chamados de artistas populares (CUNHA et al, 2006).

Contemporâneo à Nina Rodrigues, mas com um visão positiva da presença negra na cultura brasileira, foi o historiador Manoel Querino (1851-1923). Reconhecidamente importante para a história da arte baiana (FREIRE, 2012), ele inventariou profissionais ligados aos fazeres artísticos em Salvador (NUNES, 2013a). Recorreu aos arquivos da Igreja Católica e se utilizou de fontes manuscritas e orais, o que lhe rende muitas críticas 
entre os acadêmicos até hoje. A partir de biografias, estabelece um recorte entre a arte baiana antes e depois da instalação da instituição oficial de ensino de arte. Porém, ele se preocupou em estudar aqueles artistas ou artesãos que mais se aproximavam dos cânones consagrados na época, isto é, dos referenciais clássicos europeus:

\begin{abstract}
Querino, apesar de seu reconhecido empenho em valorizar a condição social e cultural do humilde, tinha formação e critérios paradoxalmente acadêmicos, desprezando a produção artística desamparada de certa escolaridade. Exigia, incondicionalmente, um teor de habilitação artesanal e uma identificação do artista ao estilo ensinado e consagrado. Nesse sentido é que ele nivela artífices hábeis a artistas criadores. (VALLADARES, 1967, p. 87-88 apud NUNES, 2013a, p. 242)
\end{abstract}

Sensível para as questões populares e para a história da arte, o negro Querino criticava a falta de apoio oficial para as artes e considerava que 0 artista estava "associado ao trabalho operário e as produções desse setor deveriam ser patrocinadas pelo Estado, 0 novo Mecenas". (SODRÉ, 2001, p.42). Estudioso da questão negra e das artes na Bahia, Manuel Querino apresentou em seus trabalhos alguns importantes artistas afrobrasileiros da época, e foi um dos raros autores que se preocuparam com a origem étnica dos artistas, ainda que limitando seus estudos à Bahia (ARAÚj0, 1988).

Pelas obras de Querino, Nina Rodrigues e Arthur Ramos, percebemos a sinalização de territórios de predominância negra como sendo lugares de fácil visibilidade das manifestações plásticas do povo descendente de escravizados. Torna-se conveniente remarcar que no período da realização das pesquisas citadas, se fixou uma das principais tendências referentes à concepção de arte afrobrasileira: a de que essa arte é produzida no âmbito das religiões de matriz africana. Durante muito tempo, esse era o ponto de partida para quem começasse a estudar a temática afrobrasileira nas artes visuais. Atualmente, tal ideia convive com outras proposições mais abrangentes acerca do locus da produção, bem como é possível questionar o reduzido número de artistas negros e negras no circuito artístico oficial. E, por um lado, ampliamos as fronteiras dos territórios de criação negro-mestiça. Por outro, temos uma tímida, mas constante, problematização da situação do negro no sistema da arte.

\title{
Laicidade, Origem Étnica e Cultura
}

A abordagem da arte afrobrasileira centrada na manufatura de artefatos sacros foi sendo transformada em meados dos anos 1950. A obra do etnógrafo Arthur Ramos, seguidor de Nina Rodrigues, foi crucial para isto. Ramos analisou não só acervos de museus da polícia - oriundos de diligências em casas de culto -, mas incluiu na pesquisa obras de artistas laicos, não ligados à religião. Esse fora o ponta pé inicial para que outros estudiosos da questão trilhassem um percurso investigativo diferente. A análise formal e a estética de obras de arte passaram a ser possíveis, ainda que amparadas nas ideias modernas e na busca do nacionalismo. (MUNANGA, 2000). 


\section{Arte afrobrasileira: contornos dinâmicos de um conceito}

Nesse momento, os artistas considerados populares ou primitivos já desfrutavam de certo prestígio no sistema de circulação de obras de arte. Galerias especializadas nesse tipo de trabalho estabeleceram-se com relativo sucesso, representando esses autores.

0 continente africano também passava por mudanças, especialmente causadas pelos ventos de libertação de antigas colônias europeias. 0 aspecto cultural passou a receber grande importância no processo de retomada e reconstrução de identidades daqueles países, o que deu lugar a iniciativas de valorização negra em dimensão mundial. Um claro exemplo desse movimento foi a realização de duas edições do Festival Mundial de Artes Negras. A primeira ocorreu em 1966, em Dacar (Senegal), e a segunda aconteceu um ano depois, em Lagos (Nigéria). A participação dos brasileiros na programação que incluía as artes plásticas foi organizada pelo crítico de arte Clarival do Prado Valladares. Entretanto, para integrar essa exposição, o artista brasileiro precisava ser negro.

Em 1968, o referido médico e professor, proveniente de uma abastada família baiana, publicou uma análise de peças alagoanas recolhidas pela polícia em 1910. Valladares em seu texto "0 Negro Brasileiro nas Artes Plásticas", reflete sobre a ausência dos negros nos espaços formais da arte, associando-se à ideia de que havia discriminação e falta de oportunidades para ele. Partindo de biografias, o autor construiu o primeiro trabalho a se debruçar sobre a origem étnica dos artistas da Academia Imperial de Belas Artes no século XIX, historicizando-os (NUNES, 2013a). Na mesma obra, apresenta ainda alguns dos artistas negros do século XVIII. 0 crítico lançou mão da descrição formal para valorizar de modo tecnicista os trabalhos desses que eram vítimas de preconceito no meio artístico.

Dedicando-se a investigar a história da arte das regiões Norte e Nordeste do Brasil, ele ampliou o campo estudando artistas eruditos e populares. Porém, considerava imprescindivel a ascendência africana para a inclusão do trabalho de um artista na categoria de arte afrobrasileira, diferentemente de Marianno Carneiro da Cunha, destacado nas décadas seguintes.

Este outro autor é uma das referências para a temática afrobrasileira na arte. Seu trabalho considerava a ideia de continuidade da arte africana em solo brasileiro, além de observar a influência branca na elaboração dos produtos artísticos (MUNANGA, 2000). Estilo, iconografia, técnica e conteúdo foram elementos examinados durante a análise de peças ritualísticas realizadas pelo professor paulista.

Com Marianno Carneiro da Cunha a temática afro-brasileira ganha a maioridade sob os paradigmas da história da arte. Ao insistir que ela está na constituição da arte brasileira, Marianno rompeu pela primeira vez a relação de etnicidade ao definir arte afro-brasileira, caracterizando-a a partir do uso de convenções estilísticas ligadas a matriz africana. (NUNES, 2013, p.121)

Marianno Carneiro da Cunha notou o uso da temática afrobrasileira em obras cujos autores coincidentemente tinham ascendência europeia, tal como se pode ler em seu principal artigo, o "Arte Afro-brasileira", publicado no livro História Geral da Arte Brasileira, organizado por Walter Zanini, em 1983. Entretanto, Marianno Carneiro da Cunha centrava sua definição de arte afrobrasileira ainda no aspecto ritualístico e funcional, 


\section{Arte afrobrasileira: contornos dinâmicos de um conceito}

o que excluía a produção de artistas contemporâneos que se inspiravam em outros aspectos das culturas africanas para a sua produção. (NUNES, 2013b).

Assim como os anteriores, os estudos de Clarival e Marianno partiram da análise da arte ritual, e depois ampliaram suas abordagens para o campo mais laico da criação. Contudo, trouxeram de modo mais técnico os aspectos formais das peças e os biográficos dos autores afrobrasileiros. Em um primeiro momento, a origem étnica do artista aparece como elemento agregador de valor, mas em seguida, reconhece-se que isso não é a essência da arte afrobrasileira. Essas pesquisas abarcaram a contribuição de artistas não-negros e não-religiosos, trazendo sub-repticiamente a questão da mestiçagem. Em síntese, eles acrescentaram ao debate sobre o conceito de arte afrobrasileira a tendência de se definir também como uma arte produzida com a temática negro-brasileira, bem como a de ser uma arte produzida por quem experimenta as culturas negras no Brasil.

\section{Arte e a Problemática Identitária Atual}

Os paradigmas de representação se alteraram especialmente a partir dos anos 1960. É relevante observar que nas décadas seguintes, se consolida o que convencionamos chamar de arte contemporânea, onde a diversidade de materiais e de possibilidades expressivas são infinitas. Embora sustentada por interesses mercadológicos hoje, a arte tem permitido que a questão identitária e a dimensão política se tornem elos bastante evidentes na criação artística. Esse processo também redimensiona a percepção das manifestações plásticas de outros grupos humanos. Em todo o planeta, o surgimento de movimentos sociais baseados em questões identitárias como o feminismo, a homossexualidade ou a negritude afetaram a produção artística.

0 etnocentrismo na arte também tem sido foco de discussões e de iniciativas que visam minimizá-lo nesse meio. Nos anos 1980, por exemplo, o uso do termo "primitivismo" foi exaustivamente debatido e criticado entre os profissionais da arte, assim como ainda hoje o é. Fato é, que a diversidade experimenta um espaço próprio mais prestigiado no sistema da arte, onde a autoria e lugar da criação fazem a diferença e agregam valor à peça. Não é por acaso que tantos produtos novos surgem no mercado da arte, tais como as artes afrobrasileira, afrocubana, africana contemporânea, asiática, entre outras "mercadorias". A recepção da obra de artistas periféricos hoje tem maior aceitação no mercado.

0 meio artístico brasileiro não ficou incólume a isso. As identidades estão presentes na produção nacional e reforçam a problemática identitária do Brasil, que é baseada na ideia da democracia racial e da mestiçagem. A arte brasileira é obrigada a rever sua própria constituição à luz da necessidade de ampliar o campo compreensivo da arte das populações historicamente desprestigiadas.

Nessa conjuntura, o adjetivo "afrobrasileiro" carrega uma força sintetizadora da experiência negra no Brasil que nenhum outro termo conseguiu abraçar. (CONDURU, 2013a). Alguns autores até utilizam o termo arte afrodescendente como sinônimo de arte afro- 


\section{Arte afrobrasileira: contornos dinâmicos de um conceito}

brasileira (CONDURU, 2007, 2013a; SILVA e CALAÇA, 2006), mas essa expressão não é suficiente para descrever as manifestações plásticas negro-mestiças no Brasil.

Compreender o que é a arte afrobrasileira não tem sido tarefa simples. Mas esse não é problema apenas dos artistas que se afirmam como negros e mestiços. Artistas brancos, de ascendência europeia, também se envolvem com a temática. Em alguns artistas, o tema afrobrasileiro é usado de modo consciente, mas esporádica ou frequentemente. Pode haver também a reedição de marcas de estilos artísticos africanos, usando temas e soluções negras - às vezes até sem se dar conta -; inclusive, podemos ter obras relacionadas ao universo ritualístico das religiões de matriz africana.

Entre os artistas negros e mestiços de nosso país, tornou-se ainda mais complicado uma classificação da arte afrobrasileira. Materializamos o problema da dificuldade da definição desse tipo de arte, pois encontrar parâmetros próprios para rotular seus trabalhos, agora, mais do nunca, ancorados no estudo biográfico e formal das obras não tem sido nada simples.

\section{Entre Discursos Verbais e Não-Verbais}

A partir de 1988, centenário da Abolição da Escravatura, os estudos sobre a arte afrobrasileira retomaram ânimo, ampliando suas publicações. Nunes (2013a, p.109) acentua 0 aumento do interesse pelo tema no país a partir dos anos 2000, por causa da lei federal número 10.639/2003 e da celebração dos 500 anos do Descobrimento do Brasil. Mas, a pesquisadora Marta Salum (2004) concluiu que grandes exposições atraíram o interesse internacional sobre a produção dos negros brasileiros. Ela ainda nos informa que o critério de participação na maioria desses eventos tem sido o pertencimento etnicorracial. Essa autora sugere que para conhecermos as manifestações das artes plásticas dos negros brasileiros é preciso estudar isoladamente a trajetória, a obra e o perfil de cada artista. Só então é que se pode tentar fazer alguma classificação histórica ou estilística.

As exposições comemorativas, realizadas nesse período em razão de datas históricas nacionais, também divulgaram a arte afrobrasileira e seu campo conceitual. Uma exposição também reflete o pensamento de um grupo; essa estrutura tem por missão a divulgação dos discursos autorizados pelo sistema das artes, pois produz falas institucionalizadas sobre as obras, sobre si e tudo o que concebe enquanto Arte (BULHÕES, 2008). Destacamos nesse contexto a atuação do artista e curador Emanoel Araújo, que organizou muitos eventos célebres, tal como a mostra A mão afro-brasileira

Somente com a exposição de 1997, A mão afro-brasileira, artistas negros que realizaram obras eruditas no século XIX foram historicizados, com a introdução destes na mostra, como artistas afro-brasileiros, muitos dos quais contemporâneos de Nina, considerando para a inclusão nesta categoria apenas o fato de serem negros e não a temática presente nas suas obras.(CUNHA et al, 2006, p.24)

Em 2004, Araújo conseguiu criar o Museu Afro-Brasil em São Paulo. Essa instituição 


\section{Arte afrobrasileira: contornos dinâmicos de um conceito}

adquiriu um notável prestígio, tornando-se uma referência para estudos sobre a arte afrobrasileira. Suas narrativas através de objetos de arte nos proporcionaram uma visão da participação do negro na história da arte ainda pouco conhecida (SOUZA, 2009), trazendo autores negros do século XIX, incluídos na mostra por seu pertencimento etnicorracial. 0 curador teve a tarefa de organizar outras exposições emblemáticas sobre 0 negro na arte brasileira. Tais eventos contribuíram para a noção e difusão dos conceitos que adotamos atualmente, como sintetiza o pesquisador Marcelo Souza (2009, p.10): "primeiro, arte afro-brasileira é produzida por artistas ligados a cultos afro-brasileiros; segundo, arte afro-brasileira é produzida por autores razoavelmente próximos da cultura negra; terceiro, arte afro-brasileira é produzida por autores que remetem ao universo plástico e social do negro no Brasil".

\section{Considerações Finais}

0 interesse da academia em contribuir para uma visão mais afirmativa das diferenças é algo recente. Ao longo da História, o conhecimento oficial assumiu uma versão unilateral e branca, eurorreferenciada, na qual o outro figura como objeto e nunca como sujeito que contribui para o desenvolvimento da humanidade. Esse tipo de perspectiva limitada se justificou e se sustentou, em certos momentos (no século XIX, por exemplo), por teorias raciológicas.

É importante ressaltar que o racismo conduziu as primeiras pesquisas sobre a cultura material dos descendentes de africanos escravizados no Brasil. Tais estudos incluíam a arte afrobrasileira, que ainda não era considerada ou prestigiada enquanto "arte". Entretanto, as mais importantes pesquisas sobre as manifestações plásticas dos negros foram originadas no campo da Medicina. Nesse tempo, a presença negra e sua influência na cultura e identidade do país preocupavam os cientistas. Com o amadurecimento das Ciências Sociais e de campos como o da Antropologia, esses estudos se multiplicaram e se consolidaram, conseguindo recentemente integrar outra área de conhecimento: a História da Arte.

Salientamos que a abordagem racista ressoou - e ainda ressoa - em todo o sistema oficial da arte, que é composto não só pela academia, mas por galerias, museus, colecionadores, entre outros elementos que se articulam para definir o que é ou não é arte. Porém, não é possível analisar a produção artística afrobrasileira desconsiderando as peculiaridades dessa população. A desigualdade que conduz a inserção social dos descendentes de africanos escravizados resultou em subjetividades e sensibilidades próprias, marcadas pela experiência negra no Brasil. Falar da arte dessa população isolando-a formal e tecnicamente não torna possível uma análise mais abrangente. Tampouco torna-se inteligível uma arte desconectada do imaginário da cultura afrobrasileira. Isolá-la em um território essencialmente negro também não facilita sua compreensão, uma vez que os conflitos e as tensões entre as culturas europeias e indígenas se fazem presentes nas expressões culturais do Brasil.

Os intelectuais citados nesse trabalho representam apenas alguns dos principais inte- 


\section{Arte afrobrasileira: contornos dinâmicos de um conceito}

ressados na questão da arte afrobrasileira, escolhidos para esse estudo inicial. Cada um deles, independentemente de suas motivações, materializou em tempos diferentes, contornos dinâmicos integram a base de sustentação do conceito de arte afrobrasileira.

A ideia de arte afrobrasileira que temos hoje nos permite entender que é uma arte produzida no âmbito das religiões de matriz africana; é elaborada por quem experimenta as culturas negras no Brasil ou feita a partir do uso da temática negro-brasileira. Seus limites com a identidade nacional são tênues. Por isso, a discussão sobre o conceito de arte afrobrasileira consolida-se como um palco de múltiplas ideias e de abordagens interdisciplinares. Ao mesmo tempo, tal produção artística hoje se firma como campo de estudos da arte nacional, ainda envolta em muitas dúvidas - e dívidas.

Os pesquisadores lembrados ao longo desse artigo, foram escolhidos para constituirmos um panorama das muitas gerações de intelectuais que tornaram possíveis as visões plurais do tema ora visitado. Contudo, eles - os autores, não representam a totalidade de estudiosos da questão artística dos afrobrasileiros. Há muitos outros trabalhos de investigação a serem a analisados, prospectados ou realizados. Os trabalhos dos estrangeiros George Preston, Roger Bastide e Kimberly Cleveland, por exemplo, são algumas sugestões para o aprofundamento posterior de nossos estudos... 


\section{Arte afrobrasileira: contornos dinâmicos de um conceito}

\section{Referências}

> ARAÚJ0, Emanoel (Org.). A mão Afro-brasileira: Significado da contribuição arte histórica. São Paulo: Tenenge, 1988.

$>$ AJZENBERG, Elza. Afro-Brasil: Arte, pesquisas e imagens modernas. In: SILVA, Dilma de Mello (Org.). Interdisciplinaridade, transdisciplinaridade no estudo e pesquisa da arte e cultura. São Paulo, Terceira Margem, 2010. p.67-70.

> BÜLL, Marcia Regina. Artistas primitivos, ingênuos, (naïfs), populares, contemporâneos afro-brasileiros. Família Silva: um estudo de resistência cultural. Dissertação de Mestrado em Educação, Arte e História da Cultura / Universidade Presbiteriana Mackenzie, São Paulo, 2007

$>$ BULHÕES, Maria Amélia. As instituições museológicas e a constituição de valores no circuito mundializado da arte. In: BERTOLI, Mariza đt STIGGER, Veronica (Orgs.) Arte, crítica e mundialização. São Paulo: ABCA: Imprensa Oficial do Estado, 2008. p.125-133

> CONDURU, Roberto L. T. Arte Afro-Brasileira. Belo Horizonte: C/ Arte, 2007

$>$ CONDURU, Roberto L. T. Negrume multicor: Arte, África e Brasil para além de raça e etnia. Acervo, Rio de Janeiro, v. 22, no 2, p. 29-44, jul/dez 2009 - Disponível em http:// revistaacervo.an.gov.br/seer/index.php/info/article/view/48 Acesso em: 04 abril $2013 a$

> CONDURU, Roberto L. T. Ogum historiador? Emanoel Araújo e a historiografia da arte afrodescendente no Brasil. In Roberto L. T.; SIQUEIRA, Vera B. (Orgs.) Anais do XXIX Colóquio do Comitê Brasileiro de História da Arte. p. 159- 166. Rio de Janeiro : Comitê Brasileiro de História da Arte, CBHA, 2009. Disponível em: http://www.cbha.art.br/coloquios/2009/anais/pdfs/anais_coloquio_2009.pdf Acesso em 13 junho 2013b

> CUNHA, Marcelo N. Bernardo da. et al. Nina Rodrigues e a Constituição do Campo da História da Arte Negra no Brasil In: Gazeta Médica da Bahia 2006;76: Suplemento $2: \mathrm{S} 23-\mathrm{S} 28$

$>$ CUNHA, Mariano Carneiro da. Arte Afro-brasileira. In: ZANINI, W. (Coord.) História Ceral da Arte no Brasil. Vol.2. São Paulo: Instituto Walter Moreira Salles, 1983. p. 975-1033

$>$ D’AVILA, Patricia Miranda. Primitivo, naïf, ingênuo: um estudo da recepção e notas para uma interpretação da pintura de Heitor dos Prazeres. Dissertação de Mestrado em Artes Visuais / Universidade de São Paulo, São Paulo, 2009

> DIAS, Mariza Guimarães. Arte africana e arte brasileira com matrizes africanas. In: CONDURU, Roberto L. T.; SIQUEIRA, Vera B. (Orgs.) Anais do XVIII Colóquio do Comitê Brasileiro de História da Arte. Rio de Janeiro: Comitê Brasileiro de História da Arte, 2009. P. $465-474$

> FREIRE, Luiz A. R. A história da arte de Manuel Querino. In: Anais do 19ć Encontro da Associação Nacional de Pesquisadores em Artes Plásticas. Cachoeira, 2010. Disponível em: 〈http://www.anpap.org.br/anais/2010/pdf/chtca/luiz_alberto_ribeiro_freire.pdf〉. Acesso em: 07 out. 2012. 


\section{Arte afrobrasileira: contornos dinâmicos de um conceito}

> FROTA, Lélia Coelho. Criação liminar na arte do povo: a presença do negro. In: ARAÚj0, Emanoel. A mão afro-brasileira: Significado da contribuição artística e histórica. São Paulo: Tenenge, 1988. p. 217-244.

> GUIMARÃES, Antonio S. A. Manoel Querino e a formação do "pensamento negro" no Brasil, entre 1890 e 1920. In: 28ć ENCONTRO NACIONAL DA ANPOCS. 2004, Caxambu. Comunicações... Disponível em: <http://svn.br.inter.net/5star/blogs/mqpensamentonegro. pdf〉. Acesso em 02 jun. 2013

> MUNANGA, Kabengele. Arte Afro-brasileira: 0 que é afinal? In: AGUILAR, Nelson (0rg) Mostra do Descobrimento: Arte Afro-brasileira. São Paulo: Associação Brasil 500 Anos Artes Visuais, 2000. p.98-111

> NUNES, Eliane. Manuel Raymundo Querino: 0 primeiro historiador da arte baiana. In: Revista Ohun, ano 3, n. 3, p. 237-261, set. 2007 Disponível em: Disponível em <http:// www.revistaohun.ufba.br/pdf/eliane_nunes.pdf >. Acesso em: 10 jun. $2013 a$.

$>$ NUNES, Eliene. Raimundo Nina Rodrigues, Clarival do Prado Valladares e Mariano Carneiro da Cunha: três historiadores da arte afro-brasileira. In: Cadernos do Programa de Pós-Graduação da Escola de Belas Artes da Universidade Federal da Bahia. Salvador, EDUFBA, ano 4, n. 4, 2007, p. 120. Disponível em: 〈http://www.portalseer.ufba.br/index. php/cppgav/article/viewFile/3973/2915>. Acesso em: 13 jun. 2013b

> RAMOS, Arthur. Arte negra no Brasil. In: ARAÚj0, Emanoel (Org.). A mão Afro-brasileira: Significado da contribuição artística e histórica. São Paulo: Tenenge, 1988, p. 247-259

> RODRIGUES, Nina. Os africanos no Brasil. Brasília: Editora Universidade de Brasília, 2004

> SALUM, Marta Heloísa Leuba. Cem anos de arte afro-brasileira. In: AGUIAR, Nelson (Org.) Mostra do Redescobrimento: Arte Afrobrasileira. São Paulo: Associação Brasil 500 Anos Artes Visuais, 2000. p.113

> SALUM, Marta Heloísa Leuba. "Imaginários negros": Negritude e Africanidade na Arte Plástica Brasileira". In: MUNANGA, Kabengele (Org.) História do negro no Brasil: o negro na sociedade brasileira, Vol. 1 - Brasília: Fundação Cultural Palmares, 2004. p.337-380

> SILVA, Dilma de Melo ; CALAÇA, Maria Cecília Félix. Arte Africana e Afro-brasileira. São Paulo: Terceira Margem, 2006

> SILVA, Raimundo N. R. da. Arte Afro-brasileira: Uma questão em aberto. Disponível em 〈http://geraaufms.blogspot.com.br/2012/10/arte-afro-brasileira-uma-questao-em.html〉. Acesso em: 03 dez. 2012.

> SODRÉ, Jaime. Manuel Querino: um herói de raça e classe. Salvador, 2001

> SOUZA, Marcelo de Salete. A configuração da curadoria de arte afro-brasileira de Emanoel Araújo. Dissertação em Estética e História da Arte / Universidade de São Paulo. São Paulo, 2009

> VALLADARES, Clarival do Prado. 0 negro brasileiro nas artes plásticas. In: ARAÚj0, Emanoel (Org.). A mão Afro-brasileira: significado da contribuição artística e histórica. São 


\section{Arte afrobrasileira: contornos dinâmicos de um conceito}

Paulo: Tenenge, 1988, p. 285-291

Nelma Cristina Silva Barbosa de Mattos, Doutoranda em Estudos Étnicos e Africanos pelo Programa Multidisciplinar em Estudos Étnicos e Africanos (POSAFRO) da Universidade Federal da Bahia (UFBA). Professora no Instituto Federal Baiano (IF Baiano).

nelma13@gmail.com 